\title{
GRAMÁTICA DO DIREITO INTERNACIONAL PENAL: AS LINGUAGENS DO CRIME E DA PUNIÇÃO
}

\author{
THE GRAMMAR OF INTERNATIONAL CRIMINAL LAW: THE LANGUAGES OF CRIME AND \\ PUNISHMENT
}

\section{Carla Veríssimo de Carli*}

\begin{abstract}
RESUMO: O trabalho examina a influência dos diferentes sistemas de justiça criminal na construção de uma dogmática internacional penal. Primeiro, discutem-se as diferentes formas de pensar sobre o crime, bem como as principais características e diferenças, externas e internas, entre a Strafrechtswissenschaft e a Common Law. Examina-se a teoria do delito de cada um desses sistemas. Segundo, é dada atenção à evolução do direito internacional penal, focando na progressiva adoção do princípio da legalidade e seu consectário, a proibição da retroatividade em matéria internacional penal. Finalmente, examina-se o Estatuto de Roma e a estrutura do delito nos crimes internacionais, para concluir que a opção feita foi pelo sistema da Common Law no âmbito internacional.
\end{abstract}

PALAVRAS-CHAVE: Direito internacional penal; Strafrechtswissenshchaft; Common Law.
ABSTRACT: This paper examines the influence of different criminal justice systems in the building of an international criminal doctrine. First, the different ways of thinking about crime are discussed, as well as the main characteristics and differences, external and internal, between Strafrechtswissenchaft and Common Law. The theory of the offense of each of these systems is examined. Second, attention is given to the evolution of International Criminal Law, focusing on the progressive adoption of the principle of nulla poena sine lege and its consequence, the prohibiton of ex post facto laws in international criminal matters. Finally, the analysis of the Rome Statute and the structure of the offence in international crimes is made, in order to reach the conclusion that the option was made for the Common Law system in the international arena.

KEYWORDS: International criminal law; Strafrechtswissenschaft; Common Law.

SUMÁRIO: Introdução. 1. Sintaxe: as formas de pensar o crime. 1.1 Sistemas de justiça criminal. 1.2 Strafrechtswissenschaft e Common Law: características e diferenças. 1.3 Teorias do delito. 2. Semântica: os desafios para a dogmática internacional penal. 2.1 O princípio da legalidade em direito internacional penal. 2.2 Crimes internacionais: estrutura bipartida ou tripartida? Considerações finais. Referências.

\section{INTRODUÇÃO}

O Direito Internacional Penal é um novo campo do direito que demanda pesquisa e produção acadêmicas. Há diversas dificuldades no trato do tema, a começar pela imprecisão terminológica, em português. Alguns autores, como Japiassú (2009, p. 4-5), utilizam o termo Direito Penal Internacional para referir o ramo do direito que define os crimes internacionais próprios e impróprios e comina as respectivas penas; que estabelece as regras relativas à aplicação extraterritorial do direito penal interno; à imunidade de pessoas internacionalmente protegidas; à cooperação jurídica internacional em todas as suas formas, até o funcionamento dos tribunais penais internacionais. Outros, como Maia Neto, diferenciam Direito Internacional Penal de Direito Penal Internacional. O primeiro é definido como o ramo das ciências jurídicas que trata dos assuntos criminais na ordem mundial, jurisdição e competência para julgamento e aplicação de sanções por órgãos vinculados à justiça

\footnotetext{
* Universidade Federal do Rio Grande do Sul.
} 
internacional devidamente reconhecida, como é o caso do Tribunal Penal Internacional. O segundo é o direito interno com implicações externas, quando a soberania da lei penal vai além das fronteiras do País que a elaborou; é a expressão da extraterritorialidade da lei penal, como exceção à regra geral da soberania e territorialidade da norma penal no espaço (caso dos $\operatorname{artigos} 5^{\circ}, 6^{\circ}$ e $7^{\circ}$ do Código Penal).

Maíra Machado, por sua vez, fala em Internacionalização do Direito Penal para designar:

[...] qualquer iniciativa ou atividade que vise a compatibilizar ou reduzir os obstáculos à interação entre a intensa circulação de pessoas, bens e capitais entre países e, com ela, a crescente visibilidade mundial de determinados problemas locais, por um lado; e a existência de nítidas fronteiras nacionais de regulação jurídico-penal, por outro. (MACHADO, 2004, p. 13)

Em espanhol, a doutrina utiliza o termo derecho penal internacional (MATUS, 2008, p. 17). Na língua inglesa adota-se a expressão international criminal law para significar o corpo de normas internacionais destinadas tanto a proibir certas categorias de condutas (crimes de guerra, crimes contra a humanidade, genocídio, tortura, agressão, terrorismo) como a responsabilizar criminalmente as pessoas que pratiquem essas condutas (CASSESE, 2008, p. 3, tradução nossa).

Os alemães diferenciam o direito penal aplicável a todos os povos, o Völkerstrafrecht (que é traduzido como Direito Penal Internacional) das normas de direito penal interno que se aplicam aos crimes cometidos fora do território - a questão da extraterritorialidade, que é o Internationales Strafrecht (traduzido como Direito Internacional Penal). Um marco importantíssimo foi a publicação do Código Penal Internacional (Völkerstrafgesetzbuch ${ }^{1}$ ), o qual prevê os crimes contra o direito internacional e outros delitos e se aplica a quem praticar as condutas ali previstas, mesmo quando os fatos ocorrem no exterior, sem ligação com o território alemão. Um dos grandes méritos desse código é determinar a aplicação de toda Parte Geral do Código Penal comum alemão ao Código Penal Internacional, o que inclui, por exemplo, as disposições sobre dolo e culpa, erro e legítima defesa, e, a não ser em condições especiais - as hipóteses dos $\S \S 3$ a 5 (ALFLEN DA SILVA, 2004, p. 15).

\footnotetext{
1 Völkerstrafgesetzbuch. Disponível em: <http://www.gesetze-im-internet.de/bundesrecht/vstgb/gesamt.pdf>. Acesso em: 22 jun. 2012.
} 


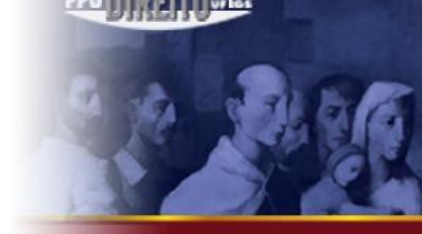

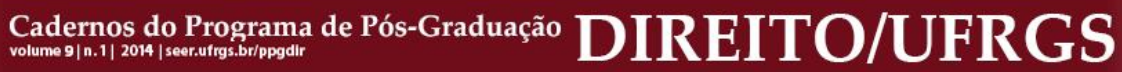

Kai Ambos define o Direito Penal Internacional (Völkerstrafrecht) como "el conjunto de todas las normas de derecho internacional que establecen consecuencias jurídicopenales" (AMBOS, 2005, p. 34).

Entretanto, as diferenças terminológicas e a imprecisão conceitual quanto a esse ramo do direito indicam apenas o início das dificuldades. O principal problema, na realidade, é a falta de uma dogmática que possa dar conta da teoria do delito em matéria internacional penal. Matus (2008), em obra importante, reflete sobre a transformação da teoria do delito em direito penal internacional. Conclui que essa dogmática está sendo paulatinamente construída, e se alimenta de duas fontes, basicamente: a Common Law e a Strafrechtswissenschaft. De todo modo, esses são dois sistemas de pensar sobre o delito que se distinguem em muitos aspectos, a começar pela base filosófica.

Além disso, o direito internacional penal não trabalha com categorias próprias do direito penal, como a prescrição e a proibição da irretroatividade da lei penal. Como justificar a punição de condutas praticadas antes mesmo da criação do tribunal que os julgou, como é o caso do Tribunal de Nuremberg? Essa hipótese não constitui justamente o que se denomina de "tribunal de exceção"? Como imputar as condutas que caracterizam os crimes internacionais aos executores e aos mandantes? Como trabalhar as teses de defesa, tanto as justificantes como as dirimentes?

Este trabalho pretende fazer uma primeira aproximação ao tema. Inicialmente, tratarei dos principais sistemas de justiça criminal existentes na atualidade. Num segundo momento, examinarei com mais detalhe os dois sistemas predominantes: a Common Law e a Strafrechtswissenschaft, com atenção para a teoria do delito de se que utilizam. Finalmente, examinarei o estágio atual da teoria do delito em direito internacional penal, para verificar se existe uma cultura jurídica predominante.

\section{SINTAXE: AS FORMAS DE PENSAR O CRIME}

Sintaxe é a parte da gramática que estuda a disposição das palavras na frase e das frases no discurso; esta é a imagem que utilizarei para tratar das formas de pensar sobre o crime, e de como essas formas de pensar organizam os elementos do delito. Isso porque parto da ideia de uma gramática do direito penal, na forma proposta por Fletcher em obra intitulada, 
justamente, The Grammar of Criminal Law. O que o autor quer é examinar as linguagens do crime e da punição:

The questions that I shall pose will be both comprehensive and tightly focused. I will seek to understand how systems of criminal law work as a whole and how the particular parts function within the whole. Because this inquiry is abstracted from any particular legal culture and because it stresses the relationship of the parts to the meaning of the whole, it is appropriate to refer to the work as a grammar of the criminal law. My aim is to elucidate the deep structure, both the syntax and the semantics, of defining and punishing crime. ${ }^{2}$ (FLETCHER, 2007, p. 8).

Para esse autor, o ponto de partida do direito é o conflito. Se não existissem conflitos, não haveria necessidade de leis para regular o comportamento humano. E a lei penal põe em evidência duas dimensões de conflito: a primeira, entre o criminoso e a vítima; a segunda, entre o suspeito e o Estado. "Victims demand justice - by which they mean that they want to see the offender punished. By contrast, suspected offenders demand fairness - a fair trial, with procedural guarantees about guilt and innocence." (FLETCHER, 2007, p. 4).

Uma terceira dimensão se revela quando o foco são os crimes que alcançam repercussão internacional: os Estados têm o dever recíproco de 'manter suas casas em ordem'. A falha nesse dever gera a impunidade, e hoje a impunidade num país é vista como uma ofensa para a comunidade internacional. De acordo com Fletcher, esse é um dos fatores que levou ao estabelecimento do Tribunal Penal Internacional, que começou a operar em julho de 2002.

Em suma, para o autor, o conflito que define a estrutura da justiça criminal hoje em dia é triplo: as vítimas chocam-se com os suspeitos do delito; os suspeitos, com o Estado; e o Estado precisa se justificar perante a comunidade internacional. A noção de delito existe em todas as sociedades, mas as culturas jurídicas desenvolveram formas distintas de lidar com esse problema.

\footnotetext{
${ }^{2}$ As questões que eu devo propor serão ambas abrangentes e estritamente focadas. Tentarei entender como os sistemas de direito penal funcionam como um todo e como as partes específicas funcionam no todo. Porque essa pergunta é abstraída de qualquer cultura jurídica em particular, e porque ela destaca a relação das partes em relação ao significado do todo, é apropriado referir-se ao trabalho como uma gramática do direito penal. Meu objetivo é elucidar a estrutura profunda, tanto a sintaxe como a semântica, da definição e da punição do crime. (em tradução livre)

${ }^{3}$ As vítimas exigem justiça - com isso querendo dizer que querem que o criminoso seja punido. Por outro lado, os suspeitos de ter praticado crime exigem justiça - um devido processo legal, com garantias processuais para apuração da culpa ou inocência. (tradução livre. Não encontrei em português uma expressão para traduzir fairness, a qual seja capaz de expressar as diferentes nuances de significado em relação à justiça).
} 


\subsection{Sistemas de justiça criminal}

Inicialmente, é preciso destacar que existem diferentes formas de pensar sobre o crime. Fletcher (2007, p. 43-58) dedicou-se a estudar as culturas jurídicas, e acabou por classificar os sistemas em quatro categorias: a) o sistema bipartido; b) o sistema quadripartido; c) o sistema tripartido; e d) a resposta holística.

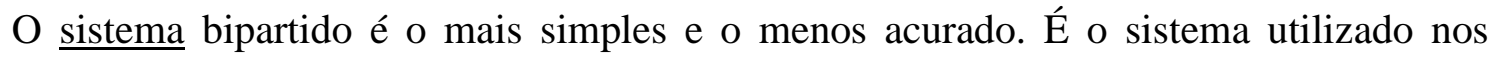
países de língua inglesa, da tradição da Common Law, mas também é usado na França e nos países francófonos. Fletcher assim o denomina porque o delito é dividido em dois elementos: o aspecto externo da conduta (actus reus) e o aspecto interno ou elemento subjetivo (mens rea).

O sistema quadripartido é uma variação do sistema bipartido que foi desenvolvido pela literatura comunista sobre responsabilidade criminal. Esse enfoque persiste na literatura russa e em vários países do Leste Europeu.

Os elementos do delito são classificados em quatro categorias: a) o sujeito do delito (o destinatário da norma); b) o aspecto subjetivo da responsabilidade (mens rea); c) o aspecto objetivo do delito (danos sociais); d) o lado objetivo da responsabilidade (actus reus).

O defeito do sistema quadripartido é o mesmo do bipartido: focaliza nos elementos da acusação e não detalha os elementos da defesa.

Já o sistema tripartido tem origem no pensamento de Kant. A doutrina penal alemã (Strafrechtswissenschaft) é a grande responsável pela elaboração da requintada teoria do delito, a qual pode admitir a existência de situações antijurídicas, porém escusáveis. "The distinction between wrongdoing and personal fault became the foundation of the German system of tought"4, afirma Fletcher (2007, p. 49). Esse sistema predomina nos países de língua alemã, ou naqueles onde ela tem influência, como na Espanha e os países da América Latina, além do Japão, Coreia e Taiwan, também Áustria, Suíça, Portugal, e em boa parte da literatura na Turquia, Grécia e Itália (MATUS, 2008, p. 17-18).

A resposta holística, o quarto grupo nas categorias criadas por Fletcher, representa a tendência de se analisar o delito como um todo, de forma a rejeitar as classificações em categorias. A ideia é a de que nenhum elemento do delito deve ser analisado isoladamente, a dualidade objetivo/subjetivo é uma simplificação cartesiana. (Apenas poderíamos falar em

\footnotetext{
${ }^{4}$ A distinção entre a conduta e a culpa tornou-se a fundação do sistema alemão de pensamento. (tradução livre)
} 
matar como uma conduta externa separada do fenômeno interno da intenção se mente e corpo fossem duas esferas completamente separadas.) Essa teoria começa em Hart e avança com Hegel, em que a punição nega o crime, que negou, primeiro, a ordem jurídica. Jakobs seria um defensor dessa linha de pensamento, na atualidade. A validação das normas é a razão para a punição dos que a violam.

Dentre os quatro sistemas expostos por Fletcher, há dois que predominam: o bipartido e o tripartido. Examinemos com mais detalhe, então, a ciência do direito penal alemão (expoente do sistema tripartido) e a Common Law (que constitui o sistema bipartido).

\subsection{Strafrechtswissenschaft e Common Law: características e diferenças}

Strafrechtswissenschaft é a ciência do direito penal, é a dogmática penal alemã. Ela também representa, no contexto deste estudo, a teoria de direito penal dos sistemas continentais ou civilistas, também conhecida como civil law.

Roxin (2000, p. 17-19) divide a história da evolução do direito penal alemão em três etapas. Na primeira delas, que vai até 1962, aproximadamente, a jurisprudência fundamentava a punição de certas condutas na doutrina cristã do direito natural. A teoria dos fins da pena foi formulada principalmente a partir da filosofia idealista alemã, que estava ligada às doutrinas da igreja. A pena servia à realização da justiça, na medida em que compensava (ou eliminava) a culpabilidade do autor, restaurando o direito transgredido. A natureza da pena corporal era retributiva. Entretanto, fortaleceu-se a posição jurídica do acusado, de acordo com a formulação da Ilustração europeia, dentro do marco de um Estado de Direito. O período do pós-guerra restaurou direitos suprimidos durante o nazismo.

A segunda fase, que perdurou até 1975, caracterizou-se pelo distanciamento da fundamentação filosófica e teológica do direito penal e pelo retorno a uma concepção secular e pragmática, como instrumento de domínio e controle social. Entram em primeiro plano os conceitos preventivos do direito penal, com a predominância da prevenção especial. $\mathrm{O}$ conceito material do delito já não mais se liga ao descumprimento de normas éticas, mas funda-se em necessidades sociais, pois "el presupuesto de cada sanción penal no surge de la contravención a la moral sino de um daño a la sociedade no evitable de otro modo"5

\footnotetext{
${ }^{5} \mathrm{O}$ pressuposto de cada sanção penal não surge da contravenção à moral, e sim de um dano à sociedade, não evitável de outro modo. (tradução livre).
} 
(ROXIN, 2000, p. 21). A tarefa do direito penal passa a ser limitada à proteção subsidiária de bens jurídicos, o que termina por restringir consideravelmente a imposição dos castigos. $\mathrm{O}$ autor esclarece que o princípio da lesividade não foi criação desse período, mas algo retomado do ideário da Ilustração. ${ }^{6}$ Era justamente o modelo de contrato social que fornecia as bases para a limitação do direito penal e sua desvinculação de postulados morais e religiosos, pois os cidadãos somente aceitavam o poder estatal para que este os protegesse em sua liberdade e segurança social. A teoria dos fins da pena se desloca, nessa fase, da retribuição à prevenção. Desvincula-se a ideia de que a culpa pode ser expiada, mediante castigo, pela tarefa social de prevenção dos delitos.

A terceira fase inicia-se a partir de 1975, e nela predominam orientações preventivas. Agora, contudo, o centro de gravidade se desloca da prevenção especial para a prevenção geral. Desse momento em diante, o rol de comportamentos que deveriam ser punidos com uma pena passa a estar menos ligado à proteção individual e estar mais preocupado com a proteção da coletividade, entendida como o conjunto da população ou grandes grupos dentro dela. Surgem novos tipos penais, especialmente os delitos econômicos, os crimes contra o meio ambiente, a responsabilidade pelo produto, grandes riscos industriais, o tráfico de drogas e outras formas de criminalidade organizada, dentro dos comportamentos que eram percebidos como uma ameaça ao conjunto da sociedade. Assim, o bem jurídico protegido somente poderia ser reconhecido de uma forma difusa, "porque los tipos delictivos, en lugar de describir formas concretas de lesión del bien jurídico, tienden a describir situaciones de peligo abstracto que se sitúan em uma fase previa a la producción del daño"7 (ROXIN, 2000, p. 25-27). O relevo à orientação preventiva geral conduz a um crescimento do direito penal a todos os âmbitos socialmente relevantes, situação que também pode ser relacionada com a emergência da sociedade de risco, muito bem descrita por Ulrich Beck (1986). Do ponto de vista dos fins da pena, depois do pouco sucesso obtido com as pretensões ressocializantes, a doutrina resignou-se em retornar à prevenção geral, justificada pela necessidade de uma garantia de segurança suficiente para a sociedade. Segundo Roxin, têm importância aqui a teoria do sistema social de Luhman, bem como a obra de Günther Jakobs, que desviaram a

\footnotetext{
${ }^{6}$ Iluminismo. Movimento intelectual do século XVIII, caracterizado pela centralidade da ciência e da racionalidade crítica no questionamento filosófico, o que implica recusa a todas as formas de dogmatismo, especialmente o das doutrinas políticas e religiosas tradicionais. Filosofia das Luzes, Ilustração, Esclarecimento, Século das Luzes (Dicionário Houaiss da Língua Portuguesa, verbetes Ilustração e Iluminismo).

${ }^{7}$...porque os tipos penais, em lugar de descrever formas concretas de lesão do bem jurídico, tendem a descrever situações de perigo abstrato que se situam em uma fase prévia à produção do dano. (tradução livre)
} 
atenção do autor individual e a dirigiram à manutenção do sistema social em seu conjunto. A teoria da prevenção geral positiva sustenta que a função da pena é exercitar a confiança na norma, de modo que todos (e cada um) a reconheçam (JAKOBS, 1997, p. 18).

Em resumo, se o direito penal estava intimamente ligado, nos primeiros tempos, à religião, à moral e aos costumes, modernamente a preocupação da Strafrechtswissenschaft é com a lesividade social das condutas às quais serão impostas as sanções criminais. Além disso, na dogmática alemã predomina a ideia da proteção de bens jurídicos, aliada ao princípio da subsidiariedade (se houverem meios menos gravosos de reprimir as condutas socialmente danosas, o direito penal não deverá ser utilizado) (ROXIN, 2003b, p. 3-4).

Vejamos agora o que caracteriza o segundo grande sistema jurídico, a Common Law. Common Law é o "judge made law", o direito que se baseia nos usos e costumes tradicionais. Segundo Ambos, até hoje não existe nenhuma codificação completa de direito penal nesse sistema que nasceu na Grã-Bretanha. Nos Estados Unidos, ao contrário, ele foi sendo substituído de maneira gradual e agora praticamente integral pelo statute law (o direito que emerge das leis escritas). (AMBOS, 2006, p. 164-165).

Common law é definida pelo Barron’s Law Diccionary (GIFIS, 2003) como

\begin{abstract}
The system of jurisprudence, which originated in England and was later applied in the United States, which is based on judicial precedent rather than statutory laws, which are legislative enactments: it is to be contrasted with civil law (the descendant of Roman Law prevalent in other western countries). Originally based on the unwritten laws of England, the Common Law is "generally derived from principles rather than rules; it does not consist of absolute, fixed and inflexible rules, but rather of broad and comprehensive principles based on justice, reason, and common sense. It is of judicial origin and promulgation. Its principles have been determined by the social needs of the community and have changed with the changes in such needs. These principles are susceptible of adaptation to new conditions, interests, relations, and usages as the progress of society may require."
\end{abstract}

\footnotetext{
${ }^{8}$ Definição do Nolo's Plain-English Law Dictionary: The body of law that developed over many years in England based on court decisions and custom, as compared to written statutes (codifications of the law). Colonists imported England's common law to what became the United States, and it survives today, greatly expanded and changed by the published decisions of American courts. Many common law principles, however, have been codified in state statutes. Only Louisiana does not take as its basic law the English common law; instead, that state's law is based on France's Napoleonic. Code. Definition provided by Nolo's Plain-English Law Dictionary. Disponível em < http://www.law.cornell.edu/wex/common_law >. Acesso em: 13 abr. 2012. Definição do Nolo's Dicionário de Inglês Jurídico: o corpo de direito que se desenvolveu durante muitos anos na Inglaterra, baseado em decisões de cortes judiciais e costume, comparado com leis escritas (codificação do direito). As colônias importaram a common law inglesa para o que se tornou os Estados Unidos da América, e ela sobrevive hoje, em muito expandida e modificada pelas publicações das decisões das cortes americanas. Muitos princípios da common law, entretanto, foram codificados em leis estaduais. Apenas a Louisiana não utiliza como sistema básico a common law inglesa, ao contrário, seu direito estadual é baseado no Código de Napoleão francês. (tradução livre)

${ }^{9} \mathrm{O}$ sistema de jurisprudência (de dizer o direito), que se originou na Inglaterra e foi posteriormente aplicado nos Estados Unidos da América, e que é baseado no precedente judicial, em vez leis escritas, que são emanadas do
} 
A Common Law anglo-americana é um sistema que teve origem na prática das cortes do Rei da Inglaterra, depois de 1066. Ela era a lei comum às cortes do rei, as quais eram pequenos enclaves em meio a muitas outras jurisdições: local folk courts, chamadas cortes do condado e as centenas que descendiam de um passado tribal. A igreja operava num sistema de cortes. Grandes proprietários de terra tinham cortes. Feiras comerciais operavam com cortes, assim como as Universidades de Oxford e Cambridge. A história da Common Law, então, é a história de como, através dos séculos, as cortes do rei foram se expandindo de um começo modesto até englobar e acabar com todas as outras jurisdições concorrentes. Nos Estados Unidos, um ponto de grande interesse é o de saber como esse sistema legal, enraizado na monarquia inglesa, pôde ser adaptado para um país fundado na premissa de que o direito e o governo poderiam existir sem um rei (LANGBEIN, 2009, p. 4).

A ideia mais comum sobre a Common Law é a de que ela não tem normas escritas, baseando-se apenas no julgamento de casos concretos. De acordo com Fletcher (2005, p. 15) "some people say that the common law is a method - a technique for deriving the law from the precedent". ${ }^{10}$ Mas, para o autor, essa visão é uma invenção moderna, que ignora a complexidade da história e, em particular, a forma pela qual grandes doutrinadores formaram a Common Law inglesa. Edward Coke e Sir William Blackstone são dois autores relevantes do século XVII que foram fundamentais na construção da doutrina desse sistema. Para eles, a Common Law era a lei da razão. Lex est ratio summa. Esses teóricos, que escreveram tratados e normas, viam a 'case law' simplesmente como a evidência do direito, mas não como o direito em si.

Fletcher (2005) concorda em que a Common Law expressa a razão, ou racionalidade. É interessante notar o quanto ela está ligada à linguagem (todos os países de língua inglesa adotaram a Common Law, ao passo que os países de tradição civilista ou continental traduziram seus códigos e suas doutrinas para dezenas de países em diferentes continentes).

poder legislativo; o qual deve ser contrastado com o sistema do direito 'civil' (descendente do direito romano e que prevalece em outros países ocidentais). Originalmente baseado em leis não escritas da Inglaterra, a Common Law é "geralmente derivada de princípios mais do que de regras; não se constitui de regras absolutas, fixas e inflexíveis, mas, ao contrário, de amplos e abrangentes princípios baseados na justiça, na razão e no senso comum. Tem origem e promulgação judicial. Seus princípios foram determinados pelas necessidades sociais da comunidade e mudaram com as mudanças de tais necessidades. Esses princípios são suscetíveis de adaptação a novas condições, interesses, relações e usos, na medida em que possa exigir o progresso da sociedade." (tradução livre).

10 “[...] algumas pessoas dizem que a common law é um método - uma técnica de derivar o direito do precedente.” (tradução livre) 
A Common Law, ao mesmo tempo, é baseada na história, e suas raízes remontam à Idade Média. Mas não há rompimento na doutrina com codificações (statutes) posteriores, não há novo começo, como ocorreu com a civil law na fase das codificações. A Common Law segue construindo desde o passado - Fletcher relembra a bela frase de Coke "out of old fields must spring grow the new corn. "11

$\mathrm{Na}$ Inglaterra, ela consiste não apenas de casos e precedentes, mas também de intervenções legislativas do parlamento (em muitas áreas da criminal law ${ }^{12}$ as intervenções da statutory law $^{13}$ ajudaram a dar os contornos das definições dos crimes). Outra característica importante é que a Common Law mescla direito material com direito processual - ao contrário da Civil Law, que tem códigos separados para direito penal e processo penal, direito civil e processo civil. A consequência dessa organização temática na legislação é a especialização dos profissionais do direito em áreas muito específicas, sejam eles professores, juízes, membros do Ministério Público ou advogados.

A forma de raciocinar juridicamente também é distinta: na análise dos casos, os americanos, por exemplo, não querem apenas extrair a regra jurídica. Eles querem saber como as questões foram apresentadas perante a corte, como a matéria foi aceita, e como os juízes acabaram decidindo. Para um civilista, a primeira pergunta é: qual é a norma aplicável? E a segunda: como se pode fazê-la valer? O advogado da Common Law quer primeiro saber como funciona o processo para depois perguntar qual é a regra jurídica que pode influenciar o resultado (FLETCHER, 2005, p. 15-21).

Examinar as diferenças entre os dois sistemas pode auxiliar na compreensão de ambos. A primeira diferença que é citada, quando eles são contrapostos, é quanto às suas fontes. No sistema da Civil Law a principal fonte do direito são os códigos, que se desenvolveram historicamente a partir do Codex Justinianus do século VI, o qual foi a lei comum a toda a Europa até o final do século XVIII, quando diversos Estados europeus elaboraram e publicaram seus próprios códigos. Um código não é apenas uma coletânea de leis; ao contrário, é o tratamento organizado e altamente sofisticado de um corpo inteiro de direito. Normalmente o código possui uma parte geral, que se aplica a todos os problemas específicos tratados na parte especial. Na Civil Law as opiniões doutrinárias que se seguem à publicação dos códigos e das leis, interpretando-os, são consideradas muito importantes, sendo

\footnotetext{
11 "É nas velhas lavouras que a primavera precisa fazer nascer o milho novo".

${ }^{12}$ Direito penal.

${ }^{13}$ Lei escrita.
} 
frequentemente citadas como base para as decisões judiciais. Já no sistema da Common Law a principal fonte do direito é a decisão judicial (judicial opinion), da forma como desenvolvida através dos séculos. As decisões dos juízes contêm princípios legais que podem ser aplicados para resolver casos futuros. Assim que um princípio do direito é desenvolvido e utilizado num caso concreto para resolver um conflito, advogados com casos similares apóiam-se no que a corte disse nesse julgamento e usam essa decisão como fundamento para sustentar que o mesmo raciocínio deve ser utilizado no julgamento do seu caso. Os juízes da Common Law estão vinculados pelas decisões que proferiram anteriormente, bem como pelas decisões das cortes superiores. O caso que foi julgado no passado e estabeleceu um princípio de direito é chamado de precedente vinculante (binding precedent). A natureza vinculante do precedente é expressa pela expressão latina stare decisis et non quieta movere, que significa manter-se no que foi decidido e não perturbar questões já resolvidas. Assim, quando se fala na doutrina do stare decisis está-se referindo à natureza vinculante das prévias decisões judiciais sobre um determinado ponto do direito (BYRD, 2001, p. 1-8).

Matus (2008) percebe diferenças externas e diferenças internas. Externamente, diferenciam-se os sistemas pela teoria do delito: a Common Law divide-o em dois elementos (actus reus e mens rea), adotando igualmente uma estrutura bipartida no processo (offense/defenses). Já a Strafrechtswissenschaft adota uma estrutura tripartida, definindo o delito como o fato típico, antijurídico e culpável.

As diferenças internas percebem-se no método adotado: o alemão é sistemático, pretende 'deduzir' as regras básicas de imputação aplicáveis a todos os casos concretos presentes e futuros a partir de estruturas externas ou dogmas (método dedutivo). A Common Law, ao contrário, não acredita que proposições gerais possam deduzir casos concretos. Nos Estados Unidos da América vigora o realismo, preconizado por Oliver Wendell Holmes, ministro da Suprema Corte americana. Matus relembra sua célebre assertiva sobre o que seja o direito: "The prophecies of what the courts will do in fact, and nothing more pretentious, are what I mean by the law"14 (2008, p. 62). Os juízes têm, nesse sistema, um caráter de lawmaker. ${ }^{15}$ Por outro lado, na Inglaterra e no País de Gales vigora o formalismo (positivismo), em decorrência do que as discussões sobre a aplicabilidade da lei ou precedentes parecem se

\footnotetext{
${ }^{14}$ As profecias sobre o que as Cortes vão fazer, de fato, e nada mais pretensioso do que isso, é o que eu entendo por direito. (tradução livre)

${ }^{15}$ Legisladores. (tradução livre)
} 
concentrar mais na validade de suas fontes ou nas conclusões que possam derivar da doutrina da ratio decidendi de um caso.

Uma segunda diferença interna refere-se à distinta aproximação filosófica. Na Strafrechtswissenschaft é fundamental a influência de Kant e Hegel, os quais, preocupados com a dignidade humana do condenado, faziam uma distinção categórica entre injusto e culpabilidade. Para a Common Law os teóricos importantes são Beccaria e Bentham, com seu liberalismo utilitarista e empírico, guiados pelo princípio liberal de que a missão do Estado não é sustentar com a força princípios ideais, mas procurar a maior felicidade possível para o maior número de pessoas.

Daí a perplexidade da Common Law com a discussão atual da Strafrechtswissenschaft acerca das finalidades ideais do direito penal (proteção de bens jurídicos versus prevenção geral positiva) frente às funções utilitárias que o primeiro sistema prevê: a dissuasão (deterrence), incapacitação (incapacitation) e reabilitação (reformation) (MATUS, 2008, p. 78-79).

As diferentes formas de pensar sobre o crime - de maneira predominante, a da Strafrechtswissenschaft e a da Common Law - podem exercer influência na construção da dogmática do direito internacional penal, pois os representantes dos diferentes países, ao negociarem os tratados internacionais (como é o caso do Tratado de Roma, que constituiu o Tribunal Penal Internacional) irão levar consigo, para a mesa dos debates, as concepções que têm sobre o delito. ${ }^{16}$ Entretanto, quando há diferenças estruturais, inevitavelmente a escolha terá que ser feita por um ou outro sistema. Para poder avaliar se existe a predominância de uma ou outra cultura jurídica no direito internacional penal, é necessário examinar as teorias do delito que utilizam.

\subsection{Teorias do delito}

A teoria do delito, também chamada de teoria do crime, teoria do fato punível, ou teoria do injusto penal, é a principal parte de dogmática penal, dentro da tradição romano-germânica da Civil Law.

\footnotetext{
16 Se bem que, como relembra Kai Ambos, a criação do Direito Penal Internacional foi e continua sendo predominantemente responsabilidade de políticos, diplomatas e, no melhor dos casos, advogados internacionais, o que deixa pouco espaço para considerações de direito penal, e, menos ainda, para reflexões mais profundas e fundamentais sobre a doutrina do Direito Penal. (AMBOS, 2008, p. 14)
} 
Fragoso define teoria do crime como "a parte da Dogmática Jurídico-Penal que estuda o crime como fato punível, do ponto de vista jurídico, para estabelecer e analisar suas características gerais, bem como suas formas especiais de aparecimento" (2004, p. 171).

Cirino dos Santos, por sua vez, vê na teoria do delito a sistematização de conceitos extraídos de um programa de política criminal formalizado em lei, aduzindo que

\begin{abstract}
a teoria do fato punível construída pela dogmática alemã constitui, talvez, o mais elaborado sistema conceitual de ciência jurídica contemporânea e, por esse motivo, representa a matrix do pensamento científico do direito penal continental-europeu e latino-americano do século XX. (CIRINO DOS SANTOS, 2004, p. vii).
\end{abstract}

Efetivamente, dentro da cultura jurídica de tradição romano-germânica, a Alemanha destacou-se na elaboração dos conceitos jurídicos e na construção de uma elaborada teoria do delito. Para Jescheck e Weigend, a teoria do delito se ocupa dos pressupostos jurídicos gerais de punibilidade, ou seja, não trata dos elementos dos crimes em concreto, mas dos aspectos do conceito de delito que são comuns a todos os fatos puníveis. Nesse sentido, trabalha as categorias da tipicidade, da antijuridicidade e da culpabilidade bem como os conceitos que a partir delas se desdobram: os elementos objetivos e subjetivos da tipicidade, os requisitos objetivos e subjetivos das causas de justificação, bem como os elementos positivos e negativos da culpabilidade. "La teoría general del delito se ocupa sobre todo de la cuestión de bajo qué condiciones pude ser imputado um hecho al autor en el nivel delictivo correspondente" 17 (JESCHECK; WEIGEND, 2002, p. 209-210).

Comprovando o que já se disse acerca da natureza desse sistema, está a afirmação dos autores de que a teoria geral do delito deve ser deduzida da lei, ou pelo menos, deve ser compatível com ela. O conceito de delito também deve estar de acordo com a finalidade e os meios do direito penal - sendo sua finalidade a proteção da convivência das pessoas na comunidade frente a transgressões jurídicas de gravidade importante; e o meio, a pena. Além disso, a teoria se fundamenta na ação do autor (comissiva ou omissiva), e não em sua personalidade (JESCHECK; WEIGEND, 2002, p. 211-212).

Cirino dos Santos explica que as origens da concepção teórica do sistema de fato punível estão na obra de Welzel, com finalização de duas monumentais construções científicas da teoria penal universal: a obra de Jescheck e Weigend, e de modo especial, o trabalho dogmático desenvolvido por Roxin (2004, p. vii e viii).

${ }_{17}$ A teoria geral do delito se ocupa sobretudo da seguinte questão: sob quais condições pode ser imputado um fato ao autor no nível delitivo correspondente. (tradução livre) 
O trabalho de Welzel foi fundamental por demonstrar, inspirado pela lição de psicólogos do pensamento e fenomenólogos, que a ação humana não é simplesmente causal, mas, ao contrário, constitui um exercício de atividade finalista.

\begin{abstract}
El carácter final de la acción, se basa en que el hombre, gracias a su saber causal, puede prever, dentro de ciertos límites, las consecuencias posibles de su conducta, asignarse, por tanto, fines diversos y dirigir su actividad, conforme a un plan, a la consecución de estos fines. Gracias a su saber causal previo puede dirigir sus diversos actos de modo que oriente el suceder causal externo a un fin y lo domine finalmente. ${ }^{18}$ (WELZEL, 2004, p. 41).
\end{abstract}

Resumidamente, na evolução da teoria do delito identificam-se três fases principais: a escola clássica (Liszt/Beling), ligada à filosofia naturalista do Século XIX; o modelo neoclássico, fundado no método neokantiano de observação/descrição e compreensão/valoração, e o modelo finalista, desenvolvido por Welzel na primeira metade do Século XX, que revolucionou todas as áreas do conceito de crime. Por causa dessa teoria, o conceito de ação final trouxe o dolo e outros elementos subjetivos para o tipo subjetivo nos crimes dolosos; separou o dolo (como vontade de realização do fato) da consciência da antijuridicidade (como elemento central da culpabilidade); disciplinou o erro (de tipo, que exclui o dolo; e o de proibição, que exclui a culpabilidade se inevitável, ou reduz a reprovação, se evitável). A antijuridicidade passou a ser constituída pelo desvalor da ação, como injusto pessoal, representado pelo dolo e outros elementos subjetivos; e o desvalor do resultado, como lesão do objeto da ação expressivo do dano social produzido. Houve também a normatização integral da culpabilidade, pela realização não justificada de um tipo de crime, com a consciência da antijuridicidade e em situação de exigibilidade de conduta diversa. Depois do finalismo foram acrescentadas outras contribuições, como a imputação objetiva do resultado e a teoria correlacionada da elevação do risco, desenvolvidas, basicamente, por Roxin, as quais simplificaram o método de compreensão e aprofundaram o nível de conhecimento dogmático do conceito de crime (CIRINO DOS SANTOS, 2004, p. 5-9).

Por sua vez, o sistema da Common Law divide a conduta, na análise do delito, em duas partes: actus reus e mens rea. Actus reus é o aspecto externo da conduta, e mens rea, o aspecto interno. A máxima do sistema é que em cada crime deve ocorrer uma união do actus

\footnotetext{
${ }^{18} \mathrm{O}$ caráter final da ação se baseia em que o homem, graças ao seu saber causal, pode prever, dentro de certos limites, as consequiências possíveis de sua conduta, e atribuir, por tanto, fins diversos e dirigir sua atividade conforme a um plano, à consecução destes fins. Graças ao seu saber causal prévio pode dirigir seus atos de modo que oriente o acontecer causal externo a um fim e o domine finalmente. (tradução livre)
} 
reus com a mens rea. A expressão latina para isso é actus non facit reus nisi mens sit rea, ou "não haverá responsabilidade criminal sem que se conjuguem a conduta externa e o estado mental". Na França, os elementos do delito são chamados de élement materiel para o ato (actus reus) e élement moral para o estado mental (mens rea).

O chamado estado mental (ou mens rea) revela uma diferença fundamental entre o sistema da Strafrechtswissenschaft, relativamente à forma pela qual um delito é atribuído a alguém. No sistema alemão (e, de forma geral, no sistema da Civil Law), a doutrina americana vê um critério psicológico de imputação. De acordo com Fletcher (FLETCHER, 1998, p. 82 e 84), a teoria psicológica pergunta se o delito estava representado na consciência do autor. A questão que é posta é se o agente decidiu praticar a conduta ou se pelo menos estava consciente de que suas ações poderiam resultar em um crime. Se ele tinha essa consciência e decidiu agir mesmo assim, então o crime pode ser imputado a ele. Já no sistema da Common Law os termos culpabilidade e mens rea são interpretados de forma a implicar que, se o autor tiver o estado mental adequado, ele poderá ser considerado responsável por sua ação, chamada de actus reus. Essa teoria é chamada por Fletcher de teoria moral. A questão não é, aqui, se o crime estava representado na consciência do autor, mas se, não importando o que estivesse em sua consciência, ele pode ser responsabilizado de forma justa, por ter cometido o ato ilícito. O enfoque não é descritivo, mas valorativo. A imputação do fato criminoso se baseia numa avaliação social e legal de todas as questões, para determinar se o agente deve ser responsabilizado criminalmente. Paralelamente, os fatores para negar a responsabilidade e a atribuição do delito são chamados de excuses (ou desculpas). Uma boa excuse significa que o ato pode ser ilícito, mas que seu autor não deverá ser responsabilizado criminalmente por ele. Na fórmula actus non facit reus nisi mens sit rea, actus reus significa a antijuridicidade, enquanto que mens rea representa a culpabilidade.

No Código Penal Modelo dos Estados Unidos ${ }^{19}$, que é tomado como paradigma para as legislações estaduais, as quais normalmente definem os delitos (felonies e misdemeanor ${ }^{20}$ ),

${ }^{19}$ A "crime" is any act or omission (of an act) in violation of a public law forbidding or commanding it. Though there are some common law crimes, most crimes in the United States are established by local, state, and federal governments. Criminal laws vary significantly from state to state. There is, however, a Model Penal Code $(M P C)$ which serves as a good starting place to gain an understanding of the basic structure of criminal liability. (disponível em http://www.law.cornell.edu/wex/criminal_law, acesso em 13.04.2012). Um crime é qualquer ato ou omissão (de um ato) que viole uma norma pública que proíba a conduta ou a imponha. Embora existam crimes da common law, a maioria dos crimes nos Estados Unidos da América são estabelecidos pelos governos locais, estaduais e federais. O direito penal varia de maneira significativa de estado para estado. Existe, contudo, um Código Penal Modelo (MPC) que serve de bom ponto de partida para obter-se um entendimento da estrutura básica da responsabilidade criminal. (tradução livre) 
são previstos quatro estados mentais: purpose, knowledge, recklessness e negligence. Fletcher (2007, p. 44) vê aí um avanço em relação aos sistemas da Common Law e a maioria dos sistemas europeus, que se contentam em distinguir entre dolo e culpa como as formas básicas do mens rea, sem que qualquer delas seja em realidade bem definida.

Apesar da simplicidade teórica, a desvantagem do sistema bipartido é não dar conta satisfatoriamente de todo o espectro de defenses que são agrupadas nas categorias de justification (justificativas) e excuses (dirimentes). Tanto a teoria psicológica como a moral parecem ter aplicação na Common Law. Necessity, duress, insanity, diminished capacity e intoxication $^{21}$ são comumente tratadas pelos teóricos como confession ou avoidance. Algumas decisões judiciais consideram que a insanidade e outras excuses negam a mens rea, enquanto outras consideram que alegações de coação, insanidade e erro quanto ao direito ficam fora dos limites da culpabilidade. Na Common Law, o promotor precisa provar o actus reus e o mens rea, enquanto que todas as outras questões são alocadas dentro das defenses, sendo, portanto, ônus da defesa comprová-las, no nível de "preponderance of the evidence"22 (FLETCHER, 1998; 2007).

As questões na Common Law tendem a ser classificadas nas categorias de offenses/defenses. O homicídio, o roubo e o estupro são offenses. Legítima defesa, estado de necessidade, consentimento, erro e insanidade são defenses. As offenses são motivos de atribuição de culpa, enquanto que as defenses são exculpatórias. O modelo bipartido reflete em alguma medida um modelo de lei privada, que divide o ônus da prova entre o autor e a defesa. O sistema acusatório importa parte desse raciocínio e tende a aplicá-lo aos casos criminais, o que explica - mas não justifica - a prática dos sistemas continentais, de base inquisitória, de deixar para o réu o ônus de provar todas as alegações de defesa (FLETCHER, 1998; 2007).

\footnotetext{
${ }^{20}$ Felonies são os delitos mais graves, em oposição a condutas de menor gravidade denominadas misdemeanors. Normalmente esses crimes são definidos pela lei estatutária (escrita) como a conduta punível com pena de morte ou de prisão por mais de um ano. Misdemeanors são as infrações punidas com pena de prisão menor que um ano. (GIFIS, 2003)

${ }^{21}$ Respectivamente: necessidade, coação, insanidade, capacidade diminuída e intoxicação.

${ }^{22}$ By preponderance of evidence é um dos níveis de prova (ou standard of proof), no processo penal da common law. O nível mais alto e exigente de prova é o "beyond a reasonable doubt", que significa que o promotor deve provar os fatos além de uma dúvida razoável. Se o júri tiver uma dúvida razoável numa questão particular, deve resolvê-la em favor do réu. Menos rigoroso que "beyond a reasonable doubt" é "by a preponderance of the evidence", que requer que os fatos sejam provavelmente mais verdadeiros do que falsos. Num nível intermediário entre ambos está "by clear and convincing evidence", que requer mais do que a preponderância da prova e menos do que a dúvida razoável. Esses níveis de exigência referem-se à quantidade de prova de um fato, no processo (tradução livre, FLETCHER, 1998, p. 16).
} 
De acordo com o autor, a teoria alemã avançou da antiga distinção entre dimensão inculpatória e dimensão exculpatória para três conceitos positivos: a) tipicidade (Tatbestand); b) antijuridicidade (Rechtswidrigkeit); e c) culpabilidade (Schuld).

Esses três conceitos abrigaram em si as causas de justificação e de exculpação, fazendo com que todas as antigas defenses ou Einwände fossem analisadas dentro de uma teoria unitária de crime. A consequência prática dessa mudança na doutrina é a de que as cortes não mais poderiam colocar o ônus sobre a defesa a comprovação das causas de justificação ou das dirimentes. Finalmente, o réu passava a receber o benefício da dúvida (in dubio pro reo) em todos os três estágios de análise. As cortes de Common Law seguiram esse movimento, passando a exigir que o promotor provasse todos os elementos da culpa além de uma dúvida razoável (beyond a reasonable doubt), mas os progressos nessa direção são incertos e os resultados, confusos (FLETCHER, 2007).

Outro aspecto importante é que os três elementos do delito, na Strafrechtswissenschaft, devem ser analisados numa ordem determinada: primeiro se avalia a tipicidade, depois a antijuridicidade, e só então a culpabilidade. Na Common Law isso não é importante, as questões relativas à mens rea podem ser analisadas tanto antes como depois do actus reus. $\mathrm{O}$ fato é que a luta entre estes dois enfoques de responsabilidade criminal dominou os debates teóricos no campo do direito internacional nos últimos cinquenta anos. Os problemas foram, primeiro, qual sistema adotar, e, segundo, como lidar com questões particulares dentro do sistema adotado. No sistema tripartido, mais rigoroso e exigente, foi de particular intensidade a discussão sobre onde deveriam ser colocados os elementos subjetivos do delito (o dolo e a culpa); se na definição do crime (tipicidade), ou se na culpabilidade. Debate similar ocorreu dentro da Common Law relativamente ao crime de homicídio, quanto à caracterização do homicídio prima facie (doloso) e do homicídio por acidente (culposo) (FLETCHER, 2007).

Expostas, em linhas gerais, as características dos dois principais sistemas jurídicos, bem como parte das dificuldades teóricas que ambos enfrentam, passa-se agora a examinar como a dogmática internacional penal tem se valido dos conceitos desenvolvidos pela Strafrechtswissenschaft e pela Common Law para a construção de sua teoria do delito. 


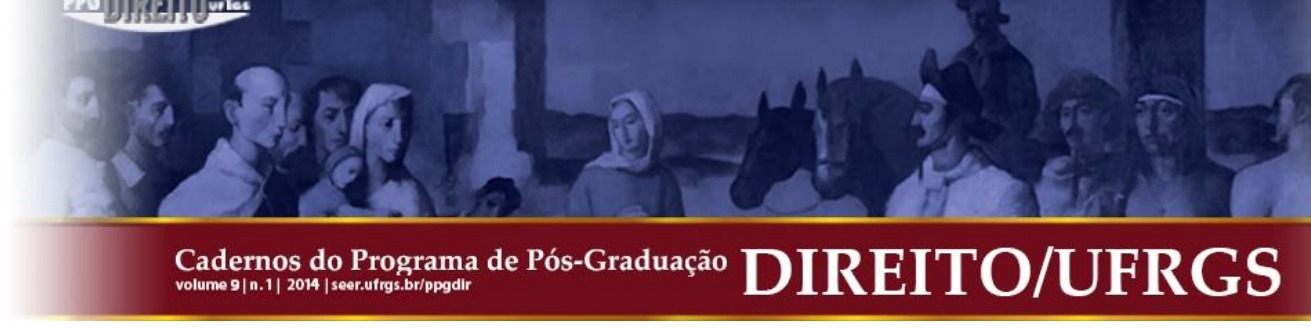

\section{SEMÂNTICA: OS DESAFIOS PARA A DOGMÁTICA INTERNACIONAL PENAL}

Seguindo na proposta de refletir sobre as linguagens do crime e da punição, a imagem da semântica parece adequada à discussão sobre os desafios enfrentados pela dogmática internacional penal. Semântica é definida como o estudo das mudanças ou translações sofridas, no tempo e no espaço, pela significação das palavras (NOVO DICIONÁRIO AURÉLIO). Podemos pensar, então, como foram adaptados os conceitos e os significados desenvolvidos pela Strafrechtswissenschaft e pela Common Law a esse novo ramo do direito internacional penal.

\subsection{O princípio da legalidade em direito internacional penal}

Uma das primeiras etapas a serem percorridas pelo direito internacional penal é a consolidação do princípio da legalidade. Nos direitos nacionais, esse princípio já é reconhecido e traz, em consequência, a proibição da retroatividade em matéria penal, tanto para os crimes como para as penas. Entretanto, no início da atuação dos tribunais internacionais surgiram discussões sobre a natureza desse princípio e sua aplicabilidade face à soberania dos Estados.

Durante os julgamentos feitos pelo Tribunal Militar de Nuremberg, que condenou 19 altos oficiais nazistas, houve grandes debates entre os juízes, alguns sustentando que a máxima nullum crimen sine lege era apenas uma regra geralmente seguida, mas que não limitaria a soberania dos Estados; enquanto que outros afirmavam exatamente o contrário, que ela representava um princípio geral de justiça (GALLANT, 2009, p. 1-3). O problema é que reconhecer isso significaria impedir a atuação do tribunal, pois todos os crimes de guerra, crimes contra a humanidade e crimes contra a paz pelos quais foram condenados os réus em Nurenberg foram criados ex post facto.

A questão da anterioridade da lei não é a única dificuldade para o atendimento do princípio da legalidade. Há também o fato de que a definição dos crimes internacionais deve ser suficientemente clara para cumprir com os requisitos do princípio nullum crimen sine lege, e isso não é sempre fácil porque as fontes do direito internacional penal incluem, além dos tratados (a lei escrita), o costume internacional e os princípios gerais de direito. Bantekas e Nash demonstram como, quando a criminalização de uma conduta ocorre em função de um 
costume internacional, a corte que irá julgá-lo pode entender que ela não tinha definição suficientemente clara sob a lei consuetudinária, por sua natureza geral, seu caráter criminal e sua gravidade, de forma a ser suficientemente compreendida e acessível, como ocorreu no julgamento do Caso Vasiljevic, pelo Tribunal Penal Internacional para a antiga Iugoslávia (BANTEKAS e NASH, 2007, p. 2 e 8).

A discussão sobre o princípio da legalidade no direito internacional evoluiu, ao ponto de Gallant afirmar que o nullum crimem, nulla poena sine lege não é apenas um princípio geral de justiça, mas representa um direito humano reconhecido internacionalmente. Contudo, mesmo com esse reconhecimento, a extensão dada ao princípio não é exatamente a mesma, para diferentes jurisdições. É por isso que, ao expor a tese de que o princípio da legalidade em direito penal, e, em especial seu componente mais importante - a proibição da retroatividade de crimes e punições - se aplica tanto no direito interno como no direito internacional penal, Gallant expressa a dificuldade de se chegar a um ponto comum:

\begin{abstract}
Because there is such diversity of legal systems worldwide, specific rules of international law developed from national systems must work for each of the major systems of law. Thus, the rule developed here is stated in terms that will make sense in the civil law, common law, and Islamic law systems, as well as the international human rights system of treaties and organizations for monitoring and enforcing the treaties $^{23}$ (GALLANT, 2009, p. 8 e 9).
\end{abstract}

Essa discussão chegou a um ponto bastante satisfatório com o Estatuto de Roma, que reconheceu, nos artigos 22 e 24, os principais aspectos do princípio da legalidade. O Estatuto usa inclusive as expressões latinas nullum crimen sine lege, no artigo 22, e nullum poena sine lege, no artigo 24. Seguindo ainda a linha da tradição da Civil Law, determina que "The definition of a crime shall be strictly construed", e proíbe expressamente o uso da analogia, no item 2 do artigo 22 (na Common Law ela é empregada, inclusive para a definição dos crimes). A definição dos crimes, com todos os seus elementos, está nos Elements of Crimes, documento que foi redigido depois do Estatuto de Roma e aprovado em 2000 pela Assembleia de Estados Parte. Os ‘elementos’ não são vinculantes para o Tribunal Internacional Penal, mas devem ser usados para auxiliá-lo nos julgamentos (HELLER; DUBBER, 2011, p. 598).

\footnotetext{
${ }^{23}$ Pelo fato de existir uma grande diversidade entre sistemas jurídicos no mundo, regras específicas de direito internacional desenvolvidas a partir de sistemas nacionais precisam funcionar em cada um dos grandes sistemas jurídicos. Assim, a regra desenvolvida aqui é formulada em termos que farão sentido na Civil Law, na Common Law e nos sistemas islâmicos de direito, assim como o sistema de tratados internacionais de direitos humanos e as organizações para monitorar e a exigir o cumprimento desses tratados. (tradução livre)
} 
O papel do Tribunal Penal Internacional na construção de uma dogmática internacional não pode ser ignorado. Segundo Heller, o Estatuto de Roma representa a tentativa mais ambiciosa da comunidade internacional para a criação de uma parte especial e de uma parte geral de direito internacional penal (HELLER; DUBBER, 2011, p. 594), e é nele que buscaremos subsídios para determinar qual teoria de delito prevaleceu, na construção dos crimes internacionais.

\subsection{Crimes internacionais: estrutura bipartida ou tripartida?}

É certo que a função do direito penal pode variar de um Estado para outro, porque ela expressa os valores de uma dada sociedade. Além disso, os delitos mudam ao longo do tempo, assim como suas sanções (AMBOS, 2006, p. 19). Partindo dessa dificuldade, entretanto, 120 países que aprovaram o Estatuto de Roma conseguiram chegar a um acordo na definição dos crimes internacionais.

Uma primeira, mas importante decisão, foi a exclusão dos chamados treaty crimes, ou os crimes previstos em tratados internacionais, tais como o tráfico de drogas, o terrorismo, a corrupção e a lavagem de dinheiro. As razões para a não-inclusão desses crimes na competência do Tribunal Penal Internacional foi a de que eles eram considerados menos graves do que os chamados core crimes e, além disso, já possuíam um arcabouço de medidas e organizações internacionais dedicadas à sua prevenção e repressão, com as quais a atuação do tribunal poderia conflitar. Definiram-se então os quatro crimes sobre os quais tem competência o Tribunal Penal Internacional, quando cometidos após $1^{\circ}$ de julho de 2002 , pelos nacionais ou no território dos países signatários: genocídio, crimes contra a humanidade, crimes de guerra e agressão. Esses crimes são genuinamente internacionais porque geram responsabilidade criminal em razão da lei internacional, não importando se são ou não tipificados nas leis domésticas dos países (HELLER; DUBBER, 2011, p. 595-596).

Os crimes internacionais estão previstos nos artigos $5^{\circ}$ a $8^{\circ}$ do Estatuto de Roma. $\mathrm{O}$ artigo $9^{\circ}$ faz referência aos elementos dos crimes, que detalham a forma e as condições de sua prática, mas, como já visto, não são vinculantes para a Corte. A terceira parte, que trata dos princípios gerais do direito internacional regula, no artigo 30, o elemento mental.

Bantekas e Nash sugerem que os redatores do Estatuto de Roma deliberadamente evitaram o uso de termos muito ligados a determinadas tradições jurídicas (não utilizaram, por 
exemplo, a expressão mens rea, preferindo falar em mental element). Da mesma forma, o artigo 31 não relaciona as justificantes e as dirimentes (justifications e excuses), preferindo agrupar todas as hipóteses de exclusão da tipicidade e da culpabilidade sob o termo genérico grounds for excluding criminal responsibility. Bantekas e Nash confirmam essa opção no Tratado de Roma, ao referirem-se aos dois tipos de 'defesas' que o acusado pode utilizar para sustentar a ausência do requisito mens rea:

\begin{abstract}
Despite the existence of the afore mentioned distinctions in both common and civil law traditions, they were not included in the ICC Statute, whose drafters agreed instead to use the general term 'exclusion of criminal responsibility', thus avoiding the need to insert terminology distinguishing between the two ${ }^{24}$. (BANTEKAS $\mathrm{e}$ NASH, 2007, p. 53)
\end{abstract}

Entretanto, apesar de tentarem não favorecer nenhuma daquelas culturas jurídicas, o fato é que o Estatuto de Roma estrutura os delitos em duas partes: os atos materiais (as condutas, referidas no artigo 30 como elemento material) e o elemento mental. Como já vimos, a estrutura bipartida do delito é própria do sistema da Common Law.

Assim, Kai Ambos conclui que o resultado de tentar desenvolver uma estrutura e o conceito de delito no Direito Penal Internacional com base na case law ${ }^{25}$ internacional e nas regras codificadas do Direito Penal Internacional é um sistema duplo correspondente às linhas do angloamericano actus reus/mens rea, e a dicotomia das eximentes (defenses) (AMBOS, 2008, p. 20).

Heller, apoiado em Kai Ambos, não tem dúvidas em afirmar a escolha do tratado pela Common Law:

\begin{abstract}
In general, however, it is clear that the Statute's "two-pronged concept of crime" is patterned after the common law, not the civil law. First, "it does not distinguish between the subjective/mental element of the offense, in the sense of a Tatvorsatz (dolus) and the blameworthiness of the act belonging to a separate and autonomous (third) level of culpability (Schuld). Second, the system "does not distinguish between wrongfulness/justification and culpability/excuse as the two- or three-fold structure of an offense as applied in the Germanic systems ${ }^{26}$ (HELLER; DUBBER, 2011, p. 601).
\end{abstract}

\footnotetext{
${ }^{24}$ Apesar da existência das distinções antes mencionadas tanto na tradição da common law como na da civil law, elas não foram incluídas no Estatuto do Tribunal Penal Internacional, cujos redatores concordaram, ao contrário, em usar o termo geral 'exclusão da responsabilidade penal', evitando assim a necessidade de inserir terminologia distinguindo entre ambas. (tradução livre)

${ }^{25} \mathrm{O}$ estudo dos casos julgados, a lei que emerge dos precedentes.

${ }^{26}$ Geralmente, contudo, fica claro que o conceito bipartido de crime do Estatuto tem o padrão da common law, e não o da civil law. Em primeiro lugar, ele não distingue entre o aspecto subjetivo/elemento mental da ofensa, no sentido de Tatvorsatz (dolo) e a culpabilidade do ato pertencendo a um nível autônomo e terciário de culpabilidade (culpa). Em segundo lugar, o sistema não distingue entre ilicitude/justificação e
} 
Na mesma linha, Matus (2008, p. 19) afirma ser dominante na atual doutrina internacionalista a ideia de que o modelo ao qual responde a jurisdição universal do Tribunal Penal Internacional é o modelo bipartido da Common Law, principalmente devido à redação do artigo 31 .

Fletcher, analisando o Estatuto de Roma, chega à mesma conclusão: o tratado distingue entre elemento material e o elemento mental que o acompanha (intent ou knowledge), e agrupa todas as hipóteses defensivas sob uma terminologia geral. Rejeita a opinião dos que pensam que a opção não teria sido pela Common Law, simplesmente porque o texto não utiliza o termo "defense". Conclui o autor que on the whole, however, the model of the common law prevails in the design of the substantive law applicable in the ICC ${ }^{27}$ (FLETCHER, 2007, p. 46).

Em direção contrária, Melendo Pardos entende não haver muito sentido em negar a influência da Common Law e de outros sistemas não baseados na estrutura continentalgermânica do delito no Estatuto de Roma, mas não vê com tanta clareza que essa distinção entre crimes e causas de exclusão da responsabilidade se possa equiparar, simplesmente, ao par angloamericano offenceldefence e, por extensão, que o crime seja formado pelo actus reus e a mens rea ${ }^{28}$ (MELENDO PARDOS, 2008, p. 56).

Quanto às causas da prevalência da teoria do delito da Common Law em detrimento daquela elaborada pela Strafrechtswissenschaft, pode-se pensar, primeiro, que a aplicação do Direito Penal Internacional foi um invento norte-americano. Kai Ambos afirma que se não fosse pela firme decisão dos Estados Unidos de levar a juízo criminosos de guerra nazistas e japoneses, Nürnberg e Tokio não haveriam existido, e, em consequência, a moderna justiça penal internacional, como a conhecemos, não teria sido construída sobre esse precedente (AMBOS, 2008, p. 15).

culpabilidade/dirimente como a estrutura bipartida ou tripartida da ofensa como aplicada pelos sistemas germânicos. (tradução livre)

${ }^{27}$ No seu todo, contudo, o modelo da common law prevalece no desenho da lei penal aplicável no Tribunal Penal Internacional. (tradução livre)

${ }^{28}$ E prossegue: "Si abrimos prácticamente cualquier Código penal, más allá de localizaciones sistemáticas, encontraremos una serie de hechos cominados con penas y unas disposiciones generales sobre la responsabilidad criminal, entre las que no será difícil que se encuentre el error, alguna referencia a presupuestos 'subjetivos', disposiciones sobre autoria y participación, tentativa, etc." (MELENDO PARDOS, 2008, P. 56). "Se abrirmos praticamente qualquer código penal, além de localizações sistemáticas, encontraremos uma serie de fatos cominados com penas e disposições gerais sobre a responsabilidade criminal, entre as quais não será difícil encontrar o erro, alguma referência a pressupostos 'subjetivos', disposições sobre autoria e participação, tentativa etc." (tradução livre) 
Por outro lado, as doutrinas germânicas no continente europeu sofrem, até certo grau, de um dogmatismo excessivo, ou seja, de uma tendência doutrinária que exagera na construção teorética, o que faz com que se afastem muito dos sistemas judiciais penais (AMBOS, 2008, p. 22). De acordo com Kai Ambos, a dogmática e a ciência jurídico penal de língua alemã não tiveram, até agora, nenhuma influência prática na configuração do Direito Internacional Penal - em razão de sua pouca abertura frente aos diferentes ordenamentos jurídicos, da falta de clareza e flexibilidade, e pelo alto refinamento de seu instrumental dogmático que resulta pouco compreensível para o observador estrangeiro, especialmente se provier da Common Law, o âmbito jurídico que forjou o Direito Penal Internacional. Além disso, não se pode esquecer do impacto do idioma na disseminação de uma cultura ou teoria: a língua inglesa domina o panorama internacional, atualmente, ao passo que o alemão é falado e compreendido num âmbito muito menor. Para piorar, os doutrinadores alemães padecem do conhecimento de outros idiomas, e raramente publicam em língua que não seja a alemã, o que faz com que a transmissão da ciência seja uma 'via de mão única'. (AMBOS, 2005, p. 49-50).

\section{CONSIDERAÇÕES FINAIS}

Apesar da ocorrência de grandes avanços normativos em matéria de direito internacional penal, proporcionados pela adoção do Estatuto de Roma, é preciso reconhecer que "uma teoria internacional sobre os fins da pena ainda se encontra em vias de desenvolvimento" (AMBOS, 2006, p. 36 e 19). Para o mesmo autor, assim como no plano nacional, os debates públicos sobre o endurecimento no direito penal no sistema de justiça internacional não contemplam a reflexão sobre o sentido e os limites da pena.

Além disso, as funções e os fins do direito penal nacional não podem ser facilmente transferidos para o direito penal internacional. Não se pode, por outro lado, negar a similitude entre esses planos, pois, como reconhece Kai Ambos, o direito penal internacional pretende criar uma consciência jurídica universal no sentido de uma prevenção geral positiva e integradora, que chama à reconciliação (AMBOS, 2006, p. 40).

Por outro lado, a escolha da preponderância do sistema da Common Law, em detrimento da Strafrechtswissenschaft pelo direito internacional penal traz algumas dificuldades adicionais, em razão da limitação da teoria do delito quanto às diversas hipóteses de justificação e exculpação que deveriam ser possíveis, nos crimes internacionais. Existem 
discussões, ainda, sobre a imputação subjetiva e a disciplina do erro no Estatuto do Tribunal Penal Internacional. A decisão de casos emblemáticos teria sido diferente, caso se tivesse adotado o sistema da Civil Law (por exemplo o caso Erdemovic, que foi julgado pelo Tribunal Internacional Penal para a ex-Iugoslávia em 2007) (AMBOS, 2006, p. 40).

Entretanto, o "consenso" interpretativo na doutrina alemã a respeito da prevalência do sistema da Common Law no Estatuto de Roma não é livre de críticas: ao invés de se tentar reconstruir o delito a partir do Estatuto, "derruba-se" a estrutura do delito em uma determinada compreensão. Mais do que tentar estabelecer um diálogo com a Common Law buscou-se a assimilação (MELENDO PARDOS, 2008, p. 81).

Em síntese, o Direito Penal Internacional está em construção. O caminho a ser trilhado pela dogmática internacional penal ainda é longo e cheio de desafios, mas proporciona também oportunidades fascinantes para o trabalho acadêmico.

\section{REFERÊNCIAS}

ALEXY, Robert. Teoría del discurso y derechos consitucionales. México: Distribuciones Fontamara, 2005.

ALFLEN DA SILVA, Pablo Rodrigo. Apontamentos sobre o Código Penal Internacional Alemão. Boletim IBCCRIM. São Paulo, ano 12, n 144, p. 15-17, novembro de 2004.

AMBOS, Kai. La parte general del Derecho Penal Internacional. Bases para una elaboración dogmática. Berlin: Konrad-Adenauer-Stiftung E.V., 2005.

. Direito Penal. Fins da Pena, concurso de pessoas, antijuridicidade e outros aspectos. Tradução de Pablo Rodrigo Alflen da Silva. Porto Alegre: Sergio Antonio Fabris Editor, 2006.

Atelier, 2008.

Principios e Imputación en el Derecho Penal Internacional. Barcelona:

BANTEKAS, Ilias; NASH, Susan. International Criminal Law. Third Edition. New York: Routledge-Cavendish, 2007. 


\section{(xa) \\ Cadernos do Programa de Pós-Graduação \\ DIREITO/UFRGS}

BECCARIA, Cesare. Dei delitti e dele pene. Milano: Mondadori, 2007.

BECK, Ulrich. Risikogesellschaft. Auf dem Web in eine andere Moderne. Frankfurt am Main: Suhrkamp Verlag, 1986.

BERCOVICI, Gilberto. Soberania e Constituição: Para Uma Crítica do Constitucionalismo. São Paulo: Editora Quartier Latin do Brasil, 2008.

BORGES, José Souto Maior. Curso de Direito Comunitário. Instituições de direito comunitário comparado: União Europeia e Mercosul. São Paulo: Saraiva, 2005.

BYRD, B. Sharon. Introduction to Anglo-American Law \& Language. Einführung in die anglo-amerikanische Rechtssprache. 2. Aufl. München, Wien und Bern: Verlage C. H. Beck/Manz/Stämpli, 2001.

CASSESE, Antonio. International Criminal Law. New York: Oxford University Press, 2008. . International Law. New York: Oxford University Press, 2005.

CASTRO, Carlos Roberto Siqueira. O devido processo legal e os princípios da razoabilidade e da proporcionalidade. Rio de Janeiro: Forense, 2006.

CIRINO DOS SANTOS, Juarez. A moderna teoria do fato punível. Curitiba: Editora Fórum, 2004.

DICIONÁRIO HOUAISS DA LÍNGUA PORTUGUESA. Rio de Janeiro: Objetiva, 2009.

DICTIONARY OF LAW. Third Edition. Teddington, Middlesex: Peter Colling Publishing Ltd, 2000.

FELDENS, Luciano. A Constituição Penal. A Dupla Face da Proporcionalidade no Controle das Normas Penais. Porto Alegre: Livraria do Advogado, 2005.

FERRAJOLI, Luigi. A soberania no mundo moderno. Nascimento e crise do Estado nacional. São Paulo: Martins Fontes, 2007. 
FLETCHER, George P. The Grammar of Criminal Law. American, Comparative and International. New York: Oxford University Press, 2007.

Press, 2005. . American Law in a Global Context. The Basics. New York: Oxford University Basic Concepts of Criminal Law. New York; Oxford: Oxford University Press, 1998.

FRAGOSO, Heleno Cláudio. Lições de Direito Penal. Parte Geral. 16 ${ }^{\text {a }}$ Edição. Rio de Janeiro: Editora Forense, 2004.

GALLANT, Kenneth S. The Principle of Legality in International and Comparative Criminal Law. New York: Cambridge University Press, 2009.

GARAPON, Antoine. PAPAPOULOS, Ioannis. Julgar nos Estados Unidos e na França. Cultura Jurídica Francesa e Common Law em uma Perspectiva Comparada. Rio de Janeiro: Lumen Juris, 2008.

GIFIS, Steven H. Barron's Law Dictionary. (Barron's legal guides). Fifth Edition. New York: Barron's, 2003.

HASSEMER, Winfried. Persona, mundo y responsabilidad. Bases para uma teoría de la imputación en Derecho Penal. Valencia: Tirant lo Blanch, 1999.

HELLER, Kevin Jon; DUBBER, Markus D. The handbook of comparative criminal law. Stanford: Stanford University Press, 2011.

JAKOBS, Günther. Derecho Penal. Parte general. Fundamentos y teoría de la imputación. Traducción de Joaquin Cuello Contreras y Jose Luis Serrano Gonzalez de Murillo. Madrid: Marcial Pons, 1997.

JAPIASSÚ, Carlos Eduardo Adriano. O direito penal internacional. Belo Horizonte: Del Rey, 2009. 
JESCHECK, Hans-Heinrich. WEIGEND, Thomas. Tratado de Derecho Penal. Parte General. Traducción de Miguel Olmedo Cardenete. Granada: 2002.

KELSEN, Hans. Jurisdição Constitucional. São Paulo: Martins Fontes, 2007.

LANGBEIN, John H. LERNER, Renée Lettow. SMITH, Bruce P. History of the Common Law. The development of Anglo-American Legal Institutions. Austin, Boston, Chicago, New York and the Netherlands: Aspen Publishers, 2009.

MELENDO PARDOS, Mariano. Imputación subjetiva y error en el Estatuto de la Corte Penal Internacional. Desafíos para la dogmática penal continental. Barcelona: Atelier, 2008.

MACHADO, Fábio Guedes de Paula. O princípio da proporcionalidade do direito penal: controle de legitimidade e limitação da intervenção estatal. Revista dos Tribunais. São Paulo, ano 100, v. 904, p. 431-450, fevereiro 2011.

MACHADO, Maíra Rocha. Internacionalização do direito penal: a gestão de problemas internacionais por meio do crime e da pena. São Paulo: Ed. 34, Edesp, 2004.

MAIA NETO, Cândido Furtado. Direito penal internacional e direito internacional penal legislação cosmopolita à luz dos direitos humanos e a norma constitucional brasileira aplicada. Disponível em <http://br.monografias.com/trabalhos-pdf901/direito-penalinternacional/direito-penal-internacional.pdf>. Acesso em: 17 jun. 2012.

MATUS, Jean Pierre. La transformación de la teoría del delito em el derecho penal internacional. Barcelona: Atelier, 2008.

MAZZUOLI, Valerio de Oliveira. O controle jurisdicional da convencionalidade das leis. São Paulo: Editora Revista dos Tribunais, 2011.

Tribunais, 2010.

Curso de Direito Internacional Público. São Paulo: Editora Revista dos

MODEL PENAL CODE, Disponível em: 〈http://www.law.cornell.edu/wex/criminal_law〉. Acesso em: 13 abr. 2012. 
Nolo's Plain-English Law Dictionary. Disponível em < http://www.law.cornell.edu/wex/common_law >. Acesso em: 13 abr. 2012.

NOGUEIRA, Roberto Wanderley. O problema da razoabilidade e a questão judicial. Porto Alegre: Sergio Antonio Fabris Editor, 2006.

NOVO DICIONÁRIO AURÉLIO. $2^{\text {a }}$ Edição. Rio de Janeiro: Aurélio Buarque de Holanda Ferreira e J.E.M.M, Editores Ltda, 1986.

PLUCKNETT, Theodore F. T. A Concise History of the Common Law. Indianapolis: Liberty Fund, 2010.

RAMOS, André de Carvalho. Responsabilidade internacional do Estado por violação de direitos humanos. Revista CEJ. Brasília, ano IX, número 29, p. 53-63, junho de 2005.

ROXIN, Claus. Strafrecht Allgemeiner Teil. Band I. Grundlagen. Der Aufbau der Verbrechenslehre. 4. Aufl. München: C.H. Beck Verlag, 2006.

Strafrecht Allgemeiner Teil. Band II. Besondere Escheinungsformen der Straftat. Munique: Editora C.H. Beck, 2003.

ARZT, Günther. TIEDEMANN, Klaus. Einfürung in das Strafrecht und Strafprozessrecht. Heidelberg: C.F. Müller Verlag, 2003.

. La evolución de la Política criminal, el Derecho Penal y el Proceso penal. Traducción de Carmen Gómez Rivery y María del Carmen García Cantizano. Valencia: Tirant lo Blanch, 2000.

SARLET, Ingo. Direitos fundamentais e proporcionalidade: notas a respeito dos limites e possibilidades da aplicação das categorias da proibição de excesso e de insuficiência em matéria criminal. Revista da Ajuris. Porto Alegre, ano XXXV, no 109, p. 139-161, março 2008 .

TANGL, Astrid. English for Lawyers and Law Students With a Short Introduction to the US Legal System. Wien: Linde Verlag, 2007.

TAVARES, Juarez. Teoria do Injusto Penal. Belo Horizonte: Del Rey, 2003. 
Völkerstrafgesetzbuch (VStGB). Disponível em: < $\quad$ http://www.gesetze-iminternet.de/vstgb/BJNR225410002.html>. Acesso em 17 jun. 2012.

WELZEL, Hans. El nuevo sistema del derecho penal - uma introducción a la doctrina de la acción finalista. Traducción y notas de José Cerezo Mir. Montevideo/Buenos Aires: Editorial B de F, 2004.

Submissão: 22/09/2013

Aceito para Publicação: 04/04/2014 